\title{
Effect of Heat and Moisture Exchange Filter on the Dead Space Ventilation in a Pediatric Patient
}

Mrunmayee Bhagwat ${ }^{1, \odot}$ Rohini M. Surve ${ }^{1}$ Prathamesh Patwardhan ${ }^{1}$

\begin{abstract}
Address for correspondence Mrunmayee Bhagwat, MBBS, DNB Anaesthesia, Flat no. 6, Sneh-Anand, Happy Colony, Lane No. 1, Kothrud, Pune 411038, Maharashtra, India (e-mail: b.mrunmayee@gmail.com).
\end{abstract}

\begin{abstract} Keywords

- heat and moisture exchange filter

- hypercapnia

- pediatric anesthesia

The use of heat and moisture exchange filter (HMEF) has become a routine standard of care in general anesthesia (GA), more so, during the current COVID-19 pandemic times. However its routine use, especially in pediatric patients, has several issues. We report a case of increased dead space ventilation in a pediatric patient due to the presence of HMEF. Hypercapnia and its cause was instantly diagnosed with two capnography sampling lines placed at two ends of the HMEF.
\end{abstract}

\section{Introduction}

Use of heat and moisture exchange filter (HMEF) during general anesthesia (GA) has been suggested, especially during prolonged surgeries to retain the moisture of the expiratory gases. Additionally, during COVID-19 pandemic, the use of HMEF is recommended between the endotracheal tube and the Y-piece of the breathing circuit to prevent aerosol contamination. ${ }^{1}$ However, it is associated with several problems such as increased airway resistance, increased work of breathing, dynamic intrinsic positive end-expiratory pressure (PEEP), increased dead space ventilation, etc. ${ }^{2,3,4}$ The problems are pronounced in adults with lung diseases and children.

We report a case of hypercapnia due to the presence of HMEF in a pediatric patient.

\section{Case Report}

A 3-year-old, $10 \mathrm{~kg}$, ASA1, male child was scheduled for a biopsy of clival lesion. Preoperatively, anesthesia machine, intubation tray, and anesthesia circuit were checked using routine protocol. New pediatric breathing circuit and pediatric size HMEF were used for the case.

As the child was uncooperative and crying, intravenous (IV) midazolam $0.05 \mathrm{mg} / \mathrm{kg}$ and IV fentanyl $2 \mathrm{mcg} / \mathrm{kg}$ were administered via the already secured IV line outside the

published online August 02, 2021
DOI https://doi.org/ $10.1055 / \mathrm{s}-0041-1731602$ ISSN 2348-0548 operating room (OR). When the child calmed down in a couple of minutes, he was wheeled into the OR, and preoxygenation was started with an appropriately sized mask. IV thiopentone $5 \mathrm{mg} / \mathrm{kg}$ and atracurium $0.5 \mathrm{mg} / \mathrm{kg}$ were administered, and the airway was secured with a $5 \mathrm{~mm}$ cuffed endotracheal tube (ETT). The HMEF and two capnography sampling lines were connected to the ETT, one distal to the HMEF (i.e., at the patient end) on ETT tube adapter with capnography displayed on the workstation monitor, and the other connected to the HMEF proximal port and toward the machine end with capnograph displayed on a separate multiparameter monitor ( - Fig. 1A). It was noticed that the capnography trace of the sampling line proximal to HMEF was of low amplitude with shortened expiratory phase and showed lower values. However, capnography trace from the sampling line distal to HMEF showed a normal trace with higher values (-Fig. 1B). The patient maintained $100 \%$ oxygen saturation and was hemodynamically stable. Adequate delivery of tidal volume was ensured. Equal air entry was heard on all lung fields with no wheeze. It was realized that the disparity in the capnography sampling readings was due to the presence of the HMEF. When the HMEF was removed, and the sampling line connected to the HMEF was placed on an adapter and in line with the other capnometry sampling line, both capnographs revealed normal traces and equal values ( - Fig. 1C, D). The surgery was completed uneventfully. (c) 2021. Indian Society of Neuroanaesthesiology and Critical Care. All rights reserved.

This is an open access article published by Thieme under the terms of the Creative Commons Attribution-NonDerivative-NonCommercial-License, permitting copying and reproduction so long as the original work is given appropriate credit. Contents may not be used for commercial purposes, or adapted, remixed, transformed or built upon. (https://creativecommons.org/licenses/by-nc-nd/4.0/).

Thieme Medical and Scientific Publishers Pvt. Ltd. A-12, 2nd Floor, Sector 2, Noida-201301 UP, India 


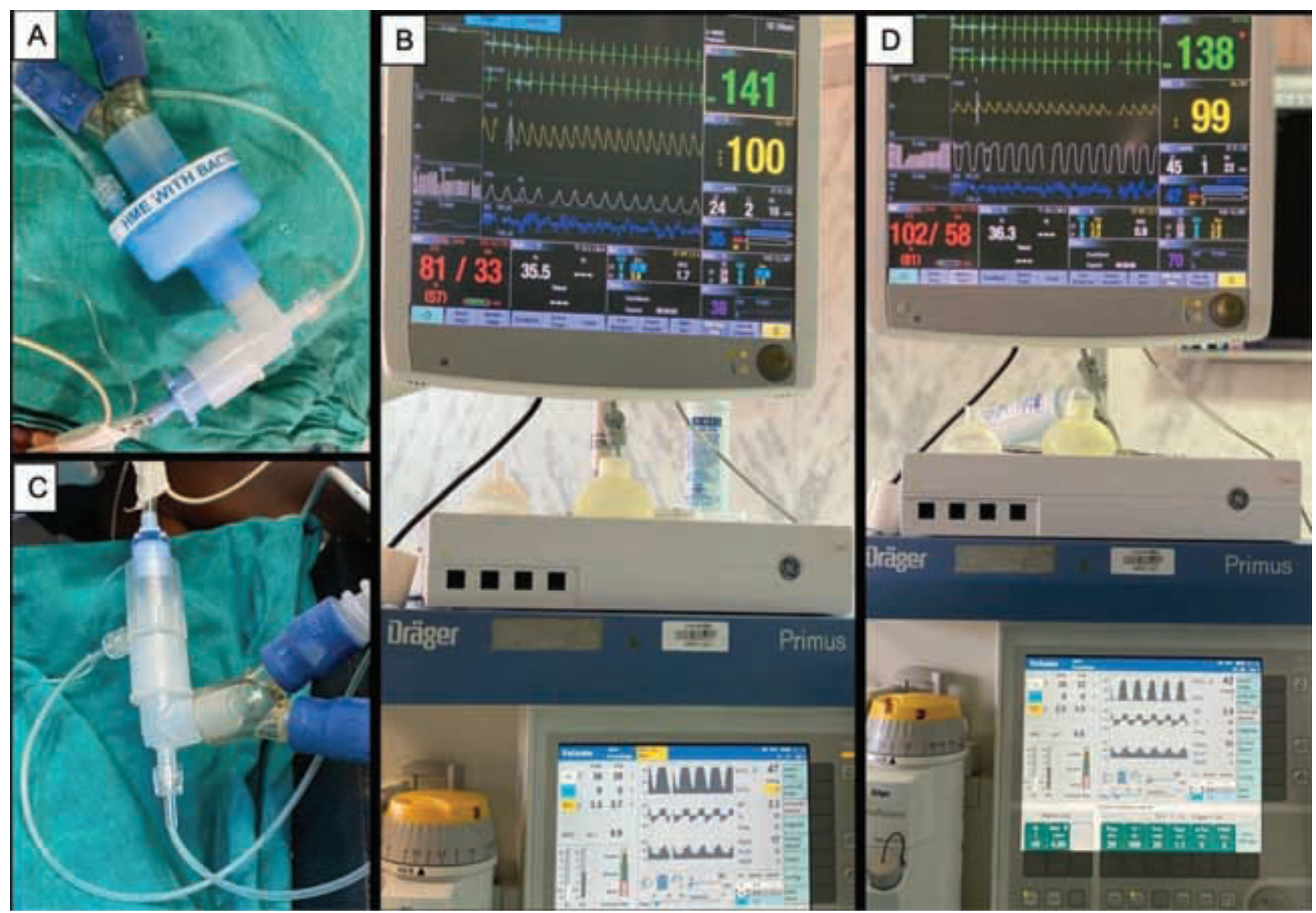

Fig. 1 Shows the initial placement of the two capnography sampling lines on either ends of the heat and moisture exchange filter (HMEF) (A), the disparity between the traces and values of the two capnography readings (B), the in-line placement of the two capnography sampling lines after removal of the HMEF (C), and normalization (approximately equal) of the traces and values of the two capnography sampling lines (D).

\section{Discussion}

During the prevailing pandemic, apart from the recommended use of HMEF to retain the heat and moisture during prolonged surgeries, irrespective of the duration of surgeries, use of HMEF is desirable at the patient end and at the expiratory end of the workstation to prevent aerosol dispersion, contamination of the OR, and contamination of the workstation. ${ }^{1}$ Further, the capnography line is advised to be put on the proximal port of the HMEF, to avoid its contamination. ${ }^{5}$ However, the use of HMEF is associated with several issues such as risk of obstruction, increase in airway resistance, increase in the dead space ventilation, etc. Hypercapnia with HMEF use in pediatric patient remains a concern due to the dead space ventilation. ${ }^{6}$ The dead space with pediatric sized HMEF is approximately 20 to $25 \mathrm{~mL}$, which can amount to 10 to $20 \%$ of the tidal volume. ${ }^{7}$ In our case, we observed disparity in the two capnometries (traces and values) in relation to the HMEF.

Our case highlights the problems which may arise due to the presence of an HMEF in the breathing circuit of a pediatric patient.

Several minutes after the induction of anesthesia, the abnormal capnography with increased end tidal $\mathrm{CO}_{2}$ reading was noticed. Tachycardia was also seen, probably secondary to the hypercapnia.
It is noteworthy that two capnography sampling lines, which were used, helped in quick detection of hypercapnia, thus avoiding the secondary untoward effects of hypercapnia.

Previous literature has shown the presence of statistically significant difference between the $\mathrm{ETCO}_{2}$ values in the machine side and patient side of the HMEF, with the underestimation of $\mathrm{CO}_{2}$ values on the machine side., ${ }^{8,9}$

If we had used only one sampling line, placed at the machine end of the HMEF, as a practice advised and observed during the pandemic times to prevent the sampling line contamination, we would have missed or delayed the diagnosis of $\mathrm{CO}_{2}$ retention which, in turn, could have dreadful implications in a case of intracranial lesion. ${ }^{5}$ Furthermore, identification of the cause of $\mathrm{CO}_{2}$ retention may have been more difficult and may have necessitated circuit disconnection and AMBU ventilation while checking the circuit patency again. This would have caused OR contamination during the COVID-19 pandemic. Thus, one must be cognizant of the challenges of HMEF use and capnometry changes in relation to HMEF, especially in pediatric patients. Considering the above concerns, it has been recommended that one must maintain a low threshold for changing the filter if there are any concerns with respect to the traces or values deviating from the normal. ${ }^{6}$ Although the sampling line contamination remains a concern with the distal position of the HMEF, which in fact 
reflects more accurate capnometry values, use of a microfilter $(0.2 \mathrm{um})$ in the sampling line or near the water trap can help circumvent this issue. ${ }^{10}$

\section{Conclusion}

Although the use of HMEF is desired during the current pandemic, irrespective of the duration of the surgery, one has to be vigilant during its use, especially in the pediatric patient.

\section{Conflict of Interest}

None declared.

\section{References}

1 Malhotra N, Bajwa SJ, Joshi M, Mehdiratta L, Trikha A. COVID Operation Theatre- Advisory and Position Statement of Indian Society of Anaesthesiologists (ISA National). Indian J Anaesth 2020;64(5):355-362

2 Wilkinson KA, Cranston A, Hatch DJ, Fletcher ME. Assessment of a hygroscopic heat and moisture exchanger for paediatric use. Anaesthesia 1991;46(4):296-299

3 Pelosi P, Solca M, Ravagnan I, Tubiolo D, Ferrario L, Gattinoni L. Effects of heat and moisture exchangers on minute ventilation, ventilatory drive, and work of breathing during pressure-support ventilation in acute respiratory failure. Crit Care Med 1996;24(7):1184-1188

4 Iotti GA, Olivei MC, Palo A, et al. Unfavorable mechanical effects of heat and moisture exchangers in ventilated patients. Intensive Care Med 1997;23(4):399-405

5 Suresh V. Airborne infection and emergency surgery: the COVID- 19 pandemic perspective. J Indian Assoc Pediatr Surg 2021;26:76-88

6 Shagufta N, Chandni S, Ajeet K, Adil A. Heat and moisture exchanger filter in a paediatric patient: A dilemma for anaesthesiologists- to use or not to use? Indian J Anaesth 2020;64(11):992-993

7 Kwon MA. The effect of a pediatric heat and moisture exchanger on dead space in healthy pediatric anesthesia. Korean J Anesthesiol 2012;62(5):418-422

8 Hardman JG, Curran J, Mahajan RP. End-tidal carbon dioxide measurement and breathing system filters. Anaesthesia 1997;52(7):646-648

9 Hardman JG, Mahajan RP, Curran J. The influence of breathing system filters on paediatric capnography. Paediatr Anaesth 1999;9(1):35-38

10 American society of anesthesiologists. COVID-19 and Anesthesia Machines and Equipment Maintenance. Available at: https:// www.asahq.org/inthe-spotlight/coronavirus-covid-19-information/anesthesia-machines-and-equipmentmaintenance. Accessed March 31, 2021 